certificate, the full technological certificate and passes in two of the advanced courses.

\section{The Dunfermline Museum}

THE Dunfermline Museum was opened in June by Dr. Douglas Allan, lately director of the Royal Scottish Museuxn, Edinburgh. This new museum has been established by the Carnegie Dunfermline Trust and will serve as a local museum of natural history and folk material. The collections came mainly from the old museum at Pittencrieff House, which has now been closed. The conversion of a private house has provided two main galleries which have been equipped with modern 'shop window' cases. One of the galleries is given over to a display of the birds and animals of West Fife in their natural habitats, and the other shows material relating to Dunfermline from the stone age to the present day. A smaller room is devoted to linen, for many years the staple industry of Dunfermline

\section{South Australian Museum}

The Records of the South Australian Museum, 14, Yo. 1 (1961), maintains the high standard of this publication and includes papers on the Aboriginal hammer-stones of South Australia, Acarina fauna, Central Australian mammals, the stratigraphy and vertebrate fauna of the Tirari Desert, South Australia, and a report on the archæological excavation of the Noola rock shelter.

\section{Experimental Alteration of the Speech-rate)}

Ir is known from the work of Dr. Wilder Penfield and his associates in Montreal that speech may be arrested or otherwise disturbed by electrical stimulation of certain areas of the cerebral cortex. In a recent paper from the Neurosurgical Service of the Foch Hospital (Suresnes-Paris), entitled "Arrest of Acceleration of Speech evoked by Thalamic Stimulation in the Course of Stereotaxic Procedures for Parkinsonism" (Brain, 84, 363; 1961), Dr. G. Guiot and his collaborators have been able to show that striking changes in rate of speaking may be produced by thalamic stimulation in the course of stereotaxic operations for Parkinsonism. Although arrest of speech is stated to be the more common phenomenon, striking acceleration in the speech-rate was noted in certain cases and changes also occurred in the strength and modulation of the voice. The locus of stimulation is reported to be the ventrolateral nucleus of the thalamus. Although these observations call for repetition on the more adequate scale, they would appear to throw an interesting light on the part played by subcortical mechanisms in the delivery and control of speech.

\section{Mineral Resources of Uganda}

TeE important part played by geological surveys in the economic advancement of under-developed territories is brought to mind by a recent publication on The Mineral Resources of Uganda (Bulletin No. 4: Compiled and edited by Dr. J. W. Barnes. Pp. $\mathrm{v}+89+2$ plates. Entebbe: Geological Survey, 1961. Shs. 25). During 1960 the mineral commodities exported from Uganda reached a record value of $£ 3.5$ million, equal to almost a quarter of the aggregate output since mining first began in 1927; and in addition industrial minerals $\theta \mathrm{X}$ ceeding $f I$ million in walue were produced for local use, and cobalt concentrates valued at $£ 1$ million were stockpiled. The principal products are blister copper and ores of tin, tungsten and beryllium; but within the next year there will be a large output of superphosphate (estimated at $£ 325,000$ per annum) for Fast African use and possibly of niobium ores for export. Since the Geological Survey began drilling for water in 1931 some 3,000 producing boreholes have been completed, yielding water supplies that have supplanted the disease-laden and ephemeral surface sources on which much of the population used to depend. In addition to reviewing resources now being exploited, the publication records various mineral potentialities of possible future interest, one of the more unusual of these being heavy water, which forms 8-12 per cent of the water in some volcanic lakes in the Ankole district. Although much of the country has still to be thoroughly prospected and, particularly in the north, to be mapped geologically, the report is a striking refutation of the view, once frequently voiced by Colonial administrators, that Geological Surveys are not revenueproducing departments.

\section{Chagas' Disease}

Preliminary surveys on the incidence of Chagas' disease in the Matalaque region, Southern Peru, by Eleazar Cordova, have shown that housing conditions favour the development of Triatoma infestans, the only vector found in this zone. Domiciliary infection shows a high incidence $(89.02$ per cent), the rate of trypanosome infection in triatomides being 51.28 per cent (41.97 per cent in bedrooms), a fact that suggests the almost certain existence of human cases of Chagas' disease. Domestic animals are frequently kept and raised within houses; such is the case, for example, of guinea pigs (84 per cent), where $T$. cruzi was found in 4 out of 32 specimens examined. Felix Naquira, Eleazar Cordova, Cesar Naquira and Enrique Rubin de Celis (Bulletin Chileno de Parasitologia, 16, No. 3; July-September 1961) have also carried out epidemiological surveys on Chagas' disease in the village of Matalaque (Tambo Valley, Southern Peru). The application of xenodiagnosis revealed an incidence of $34 \cdot 67$ per cent (43 out of 124 individuals surveyed) of Trypanosoma cruzi infection, whereas complement fixation procedures yielded $32 \cdot 23$ per cent positive cases ( 30 out of 93 individuals). Xenodiagnosis was also positive in four guinea pigs and one dog. The results obtained with the two methods were not entirely concurrent.

\section{Fellowships in Engineering Study and Fundamental Research in Plastics}

Princeton University is offering a number of fellowships in engineering study and fundamental research in plastics leading to the M.Sc. and Ph.D. degrees, particularly suited to chemical, electrical and mechanical engineers, and to chemists and physicists. Instruction covers basic theory and properties, and principles of evaluation, production, fabrication, design and application of materials, as well as the chemistry of plastics. The programme includes lecture and laboratory classes, and contact with industrial plants representing various interests of the plasties industry. Fellowships with stipends valued at 1,500 dollars-2,100 dollars are available to applicants holding a first degree in engineering or physical science from a recognized institution. Further information can be obtained from Prof. Louis F. Rahm, Plastics Laboratory, Princeton University, Princeton, N.J. 